\title{
Helicobacter pylori colonization of the adenotonsillar tissue: Fact or fiction?
}

\author{
Sérgio Vilarinho ${ }^{\mathrm{a}, 1}$, Nuno M. Guimarães ${ }^{\mathrm{b}, \mathrm{c}, 1}$, Rui M. Ferreira ${ }^{\mathrm{b}, \mathrm{d}, 1}$, Bárbara Gomes ${ }^{\mathrm{e}}$, Xiaogang Wen $^{\mathrm{b}}$, \\ Maria J. Vieira ${ }^{c}$, Fátima Carneiro ${ }^{\text {b,d,e }}$, Tiago Godinho ${ }^{a}$, Ceu Figueiredo ${ }^{\text {b,d,* }}$ \\ a Serviço de Otorrinolaringologia, Hospital de São Marcos, Braga, Portugal \\ ${ }^{\mathrm{b}}$ Institute of Molecular Pathology and Immunology of the University of Porto (IPATIMUP), Porto, Portugal \\ ${ }^{\mathrm{C}}$ Institute for Biotechnology and Bioengineering (IBB), Centre of Biological Engineering, Universidade do Minho, Braga, Portugal \\ ${ }^{\mathrm{d}}$ Faculty of Medicine of the University of Porto, Porto, Portugal \\ e Department of Pathology, Hospital de S. João, Porto, Portugal
}

\section{A R T I C L E I N F O}

\section{Article history:}

Received 23 March 2010

Received in revised form 13 April 2010

Accepted 14 April 2010

Available online 8 May 2010

\section{Keywords:}

Helicobacter pylori

Adenotonsillar tissue

PCR

Rapid urease test

Immunohistochemistry

PNA-FISH

\begin{abstract}
A B S T R A C T
Objective: The transmission of the gastric pathogen Helicobacter pylori involves the oral route. Molecular techniques have allowed the detection of $H$. pylori DNA in samples of the oral cavity, although culture of $H$. pylori from these type of samples has been sporadic. Studies have tried to demonstrate the presence of H. pylori in adenotonsillar tissue, with contradictory results. Our aim was to clarify whether the adenotonsillar tissue may constitute an extra gastric reservoir for $H$. pylori.

Methods: Sixty-two children proposed for adenoidectomy or tonsillectomy were enrolled. A total of 101 surgical specimens, 55 adenoid and 46 tonsils, were obtained. Patients were characterized for the presence of anti-H. pylori antibodies by serology. On each surgical sample rapid urease test, immunohistochemistry, fluorescence in situ hybridization (FISH) with a peptide nucleic acid probe for $H$. pylori, and polymerase chain reaction-DNA hybridization assay (PCR-DEIA) directed to the vacA gene of $H$. pylori were performed.

Results: Thirty-nine percent of the individuals had anti-H. pylori antibodies. Rapid urease test was positive in samples of three patients, all with positive serology. Immunohistochemistry was positive in samples of two patients, all with negative serology. All rapid urease test or immunohistochemistry positive cases were negative by FISH. All samples tested were negative when PCR-DEIA for $H$. pylori detection was used directly in adenotonsillar specimens.

Conclusions: The adenotonsillar tissue does not constitute an extra gastric reservoir for $H$. pylori infection, at least a permanent one, in this population of children. Moreover, techniques currently used for detecting gastric $H$. pylori colonization are not adequate to evaluate infection of the adenotonsillar tissues.
\end{abstract}

(c) 2010 Elsevier Ireland Ltd. All rights reserved.

\section{Introduction}

Helicobacter pylori is considered the most frequent chronic infection of humans, with more than half of the world's population being infected [1]. $H$. pylori is a microaerophilic, gram negative bacterium that persistently colonizes the human gastric mucosa. The infection is usually acquired early in childhood and can persist for the lifetime of the host if not treated [1]. H. pylori infection occurs worldwide, but its prevalence is significantly different between countries [2]. Studies of risk factors for $H$. pylori infection

\footnotetext{
* Corresponding author at: Institute of Molecular Pathology and Immunology of the University of Porto (IPATIMUP), Rua Dr. Roberto Frias S/N, 4200-465 Porto, Portugal. Tel.: +351 225570779; fax: +351 225570799 .

E-mail address: cfigueiredo@ipatimup.pt (C. Figueiredo).

${ }^{1}$ Equal contribution.
}

have associated the prevalence of infection with the socioeconomic indicators, with higher prevalence in developing regions and lower prevalence in developed regions [2].

The transmission of $H$. pylori is still poorly understood, but the faecal-oral and the oral-oral are the most consensual routes of transmission $[1,2]$. The presence of $H$. pylori in the oral cavity has been detected in samples from supragingival plaque, dental plaque and saliva by polymerase chain reaction [2-4], but culture of the bacteria from this type of samples has been sporadic. More recently, it has also been suggested that adenotonsillar tissues may be a reservoir for $H$. pylori, and several studies evaluated the presence of $H$. pylori in adenoid and tonsil specimens [5-7]. However, results have been contradictory and, most importantly, techniques used to detect $H$. pylori in these tissues were not appropriate. Therefore, our aim was to clarify whether the adenotonsillar tissue may constitute an extra gastric reservoir for $H$. pylori. We have studied 62 children proposed for 
adenoidectomy and/or tonsillectomy, and a total of 101 samples ( 55 adenoid and 46 tonsils) were characterized for the presence of $H$. pylori using different techniques.

\section{Materials and methods}

\subsection{Patients and surgical procedures}

Patients were consecutively selected from the surgical waitlist for adenoidectomy and/or tonsillectomy, with or without treatment of middle ear disease, and that had not been treated with antibiotics nor with proton pump inhibitors on the 4 weeks prior to surgery. Sixty-two patients (mean age $=7.9 \pm 5.5$ years and male/ female ratio of 1:1.2) fulfilled these criteria and were recruited for this study. Thirty-nine patients (62.9\%) underwent adenoidectomy, 16 patients (25.8\%) underwent adenotonsillectomy and seven patients (11.3\%) underwent tonsillectomy at the Hospital São Marcos, Braga, Portugal. Routine surgical indications for adenotonsillectomy were followed. All patients were operated under general anaesthesia. Blockage of gastro-pharyngeal reflux was obtained with gauze placed on the hipopharynx after oro-tracheal intubation and before trendlenburg positioning. Protocols followed in the study were in accordance with the institutional ethical standards. Informed consent was obtained from the patients' parents. Samples were delinked and unidentified from their donors.

\subsection{Serology}

Serum samples were used for detection of IgG antibodies against $H$. pylori, using the Pyloriset EIA-G III Kit (Orion Diagnostics, Espoo, Finland). The assay was performed following the manufacturer's instructions.

\subsection{Rapid urease test}

A $1 \mathrm{~mm}^{3}$ sample from each surgical specimen was immersed in urea broth medium containing phenol red (Fluka, Buchs, Switzerland) and incubated for $24 \mathrm{~h}$ at $37^{\circ} \mathrm{C}$. At the end of that time period, colour changes in medium were registered.

\subsection{Histology and immunohistochemistry}

Surgical specimens were formalin fixed, paraffin embedded, and sections of $3 \mu \mathrm{m}$ were cut. Slides were deparaffinised in xylol and hydrated with grade ethanol concentrations, and stained with haematoxylin and eosin, modified Giemsa and with a rabbit antihuman polyclonal antibody against $H$. pylori (Cell Marque, CA, USA). Briefly, antigen retrieval was performed by microwave pretreatment in $10 \mathrm{mmol} / \mathrm{L}$ citrate buffer $(\mathrm{pH} \mathrm{6.0)}$ for $15 \mathrm{~min}$. Endogenous peroxidase activity was blocked with hydrogen peroxide block solution (Labvision, UK) for $10 \mathrm{~min}$. After washing in phosphate buffered saline (PBS), sections were incubated for 30 min with primary antibody (1:500). Staining was achieved using Dako RealTM EmvisionTM/HRP rabbit/mouse polymer, for $30 \mathrm{~min}$ at room temperature. Binding was detected using diaminobenzidine (DAB), which upon oxidation forms a stable brown end-product. Nuclei were slightly counterstained with Mayer's haematoxylin. Gastric biopsies positive for $H$. pylori infection were used as positive controls. Slides were visualized by two experienced pathologists that were blind to the patients' clinical data.

\subsection{PNA-FISH}

H. pylori was detected in the adenotonsillar samples using the Hpy769 probe, a peptide nucleic acid probe (PNA) that is highly specific and sensitive for the detection of $H$. pylori [8]. The surgical specimens were deparaffinised and rehydrated in xylol and ethanol. Samples were immersed twice in xylol for $15 \mathrm{~min}$, and in decreasing concentrations of ethanol for $5 \mathrm{~min}$, and were finally washed with distilled water for $10 \mathrm{~min}$. Samples were allowed to air dry and the fluorescence in situ hybridization (FISH) procedure was performed as described in Guimarães et al. [8].

\subsection{DNA isolation}

DNA was isolated of $8 \mathrm{~mm}^{3}$ fragments from all surgical specimens using the DNA Invisorb Spin Tissue Mini Kit (Invitek, Berlin, Germany). The extraction was performed following the manufacturer's instructions. In a subset of cases, the whole surgical specimen was fully homogenized in Tris-EDTA buffer (10 mM Tris $\mathrm{pH} 7.5,1 \mathrm{mM}$ EDTA) using an ultraturax homogenizer and DNA was isolated.

\section{7. $P C R$ and DEIA}

Detection of the vacA gene of $H$. pylori was performed using primers VA1F and VA1XR, described previously [9]. PCR reaction mixtures were performed in a volume of $25 \mu \mathrm{L}, 1 \times$ PCR Buffer, $2.5 \mathrm{mmol} / \mathrm{L}$ of $\mathrm{MgCl}_{2}, 0.25 \mathrm{mmol} / \mathrm{L}$ dNTPs, $0.25 \mathrm{U}$ AmpliTaq Gold, and 25 pmol of each primer. PCR was performed with 9 min predenaturation at $95^{\circ} \mathrm{C}$, followed by 40 cycles of $30 \mathrm{~s}$ at $95^{\circ} \mathrm{C}, 45 \mathrm{~s}$ at $50{ }^{\circ} \mathrm{C}$, and $45 \mathrm{~s}$ at $72{ }^{\circ} \mathrm{C}$. Final extension was performed for $10 \mathrm{~min}$ at $72{ }^{\circ} \mathrm{C}$. Amplimers carrying a biotin moiety at the $5^{\prime}$ terminus of the reverse primer were detected in a microtiter well-based DNA hybridization assay (DEIA) using a specific general probe for the vacA gene [10,11]. DNA isolated from $H$. pylori Tx30a (ATCC 51932, American Type Tissue Culture) and 26695 (ATCC 700392) strains was used as reference.

\subsection{Statistical analyses}

Age distribution between $H$. pylori seropositives and seronegatives was analysed by the Student's $t$-test. Association between gender and $H$. pylori serology was assessed by the Pearson ChiSquare test. Logistic regression models were computed with Statview for Windows software (version 5.0; SAS Institute Inc., Cary, NC). Differences in data values were considered significant at $p$ values lower than 0.05 .

\section{Results}

The study population was constituted by 62 children living in the North of Portugal, which were indicated to surgery due to adenotonsillar hypertrophy (47 cases), infection (5 cases) or both (10 cases). Sixty-two blood samples and 101 surgical samples (55 adenoids, 23 left tonsils and 23 right tonsils) were obtained.

The presence of anti-H. pylori antibodies in serum was detected in $24(39 \%)$ cases. Infected patients were older than uninfected patients $(p=0.013)$ and were more frequently females $(p=0.044)$ (Table 1 ). In a logistic regression analysis, including both gender and age in the model, only age remained associated with $H$. pylori seropositivity $(p=0.039)$.

To evaluate the presence of $H$. pylori in the adenotonsillar tissues, we have used the rapid urease test, immunohistochemistry with a polyclonal anti-H. pylori antibody, FISH with a specific $H$. pylori PNA probe, and PCR-DEIA for $H$. pylori vacA gene (Table 2 ).

The rapid urease test was positive in two (3.6\%) adenoid and in two (4.3\%) tonsil specimens from three patients. All urease test positive samples were from patients infected with $H$. pylori as evaluated by serology. 
Table 1

Characteristics and H. pylori serology in the studied individuals.

\begin{tabular}{llll}
\hline & \multicolumn{2}{l}{ Serology } & \multirow{2}{*}{$p$ value $^{*}$} \\
\cline { 2 - 3 } & Negative $(n=38)$ & Positive $(n=24)$ & \\
\hline Age (average \pm SE) & $6.5 \pm 0.6$ & $10.1 \pm 1.5$ & 0.013 \\
Gender & & & \\
$\quad$ Female & 17 & 17 & 0.044 \\
Male & 21 & 7 & \\
\hline
\end{tabular}

Univariate analysis; SE: standard error.

Table 2

H. pylori detection in adenotonsillar tissues by different methods.

\begin{tabular}{lll}
\hline Method & Adenoids $(n=55)$ & Tonsils $(n=46)$ \\
\hline Rapid urease test & $2(3.6 \%)$ & $2(4.3 \%)$ \\
Immunohistochemistry & $0(0 \%)$ & $3(6.5 \%)$ \\
PNA-FISH & $0(0 \%)$ & $0(0 \%)$ \\
PCR-DEIA & $0(0 \%)$ & $0(0 \%)$ \\
\hline
\end{tabular}

PNA-FISH: peptide nucleic acid-fluorescence in situ hybridization; PCR-DEIA polymerase chain reaction-DNA hybridization assay.

Immunohistochemistry was positive in three tonsil specimens from two patients (Fig. 1), and these patients were $H$. pylori serology negative. FISH using a specific PNA probe for $H$. pylori was negative in paraffin cuts consecutive to those used for immuno- histochemistry (Fig. 2). PNA-FISH was negative in all studied specimens.

The presence of $H$. pylori in the adenotonsillar samples was also assessed by PCR, directed to the vacA gene, which is present in all strains of $H$. pylori. In order to improve the sensitivity of the PCR, amplimers were hybridized with a vacA specific probe in DEIA assays. All samples were negative for the presence of $H$. pylori. To exclude sampling bias, in a subset of cases corresponding to those that were ELISA positive, DNA isolation was performed after fully homogenizing the whole surgical specimen. All cases were negative for $H$. pylori.

\section{Discussion}

Data concerning the presence of $H$. pylori in adenoids and/or tonsils are inconsistent. In this study we have initially characterized all patients for the presence of serum anti-H. pylori IgG antibodies. In agreement with previously published data on the prevalence of $H$. pylori infection in the Portuguese population in paediatric age, $39 \%$ of the patients were $H$. pylori positive [12]. The presence of the infection was associated with older patients and, in keeping with previous studies, gender did not constitute a risk factor for $H$. pylori infection [13].

To clarify whether $H$. pylori is present in the adenotonsillar tissues of these children, we have used a variety of approaches
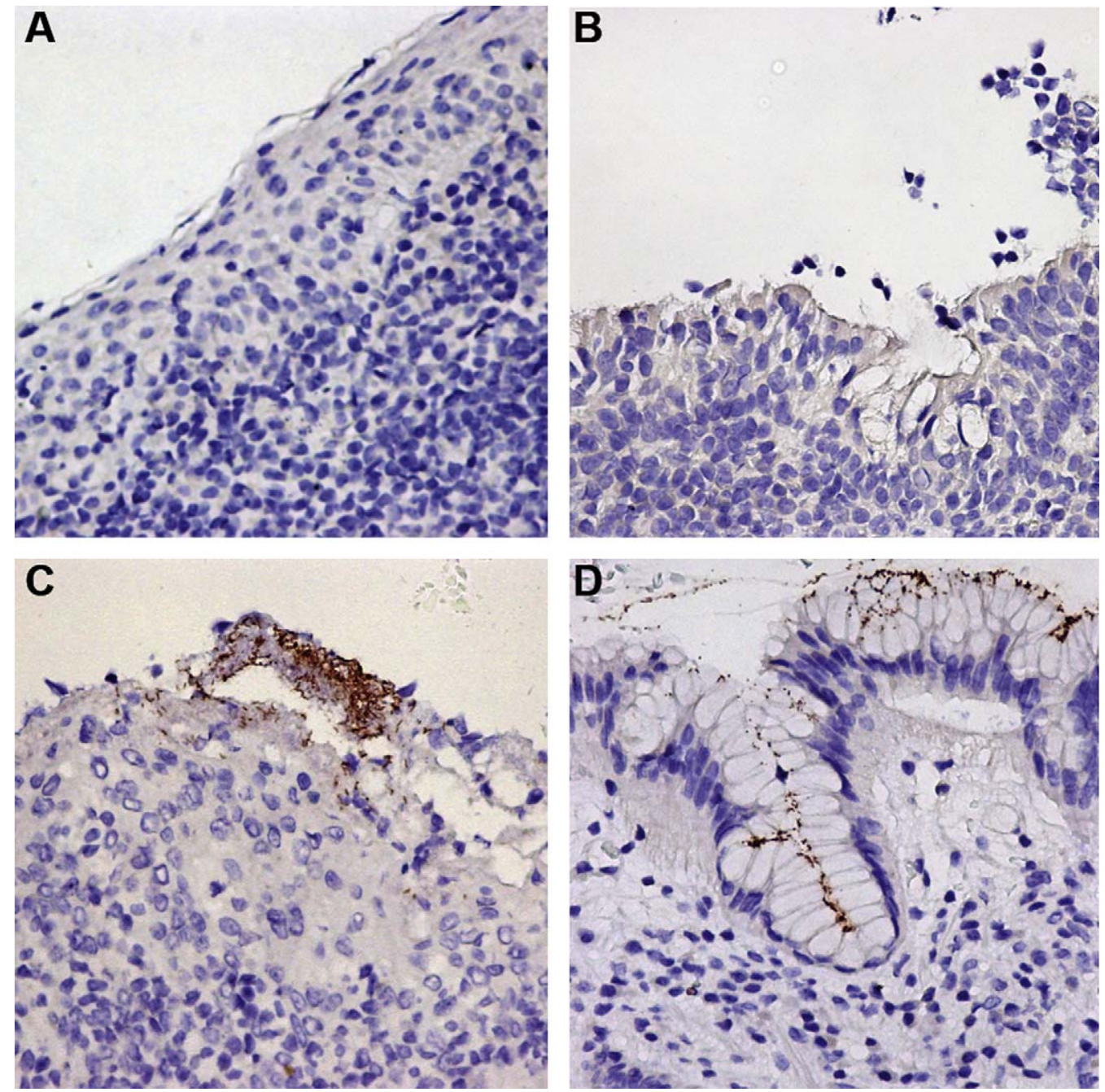

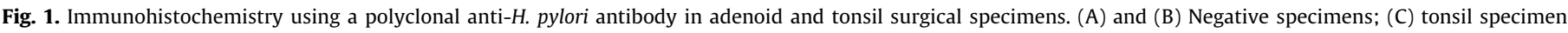
showing $H$. pylori-like microorganisms; (D) H. pylori-infected gastric mucosa used as positive control. 

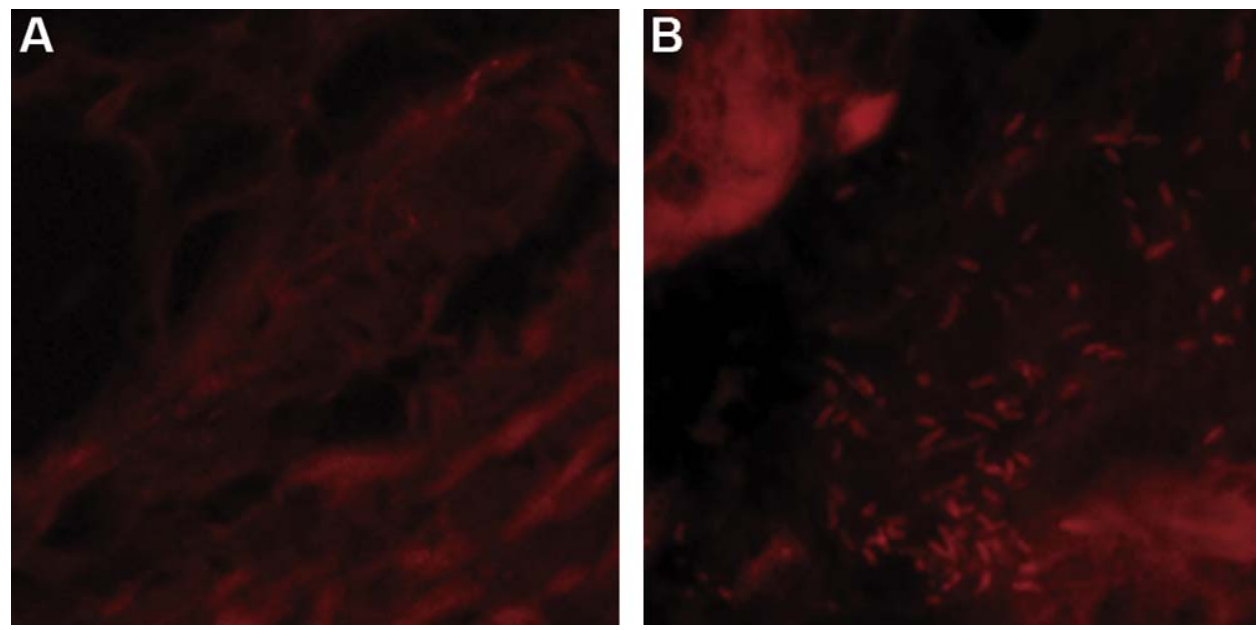

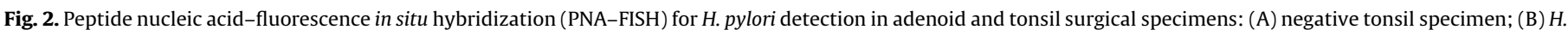
pylori-infected gastric mucosa used as positive control.

directly aimed at the tissue samples. Therefore, each adenoidal and tonsillar specimen was submitted to rapid urease test, immunohistochemistry, PNA-FISH and PCR-DEIA. We detected ureasepositive microorganisms in four tissue specimens of three patients with positive $H$. pylori serology. However, we also demonstrated by immunohistochemistry, PNA-FISH and PCR-DEIA that these urease-producing microorganisms were not $H$. pylori. Though immunohistochemistry was positive in three tonsil specimens from two patients, these specimens were $H$. pylori-negative by PNA-FISH and PCR-DEIA, and the patients did not present antibodies anti-H. pylori.

All adenotonsillar specimens included in this study were negative when PNA-FISH or PCR-DEIA were used. The PNA-FISH method has been previously tested in different types of samples and with different microorganisms, and has shown a high specificity for $H$. pylori [8]. PCR is recognized as having high specificity if the target gene and the primers are carefully chosen. In this study, we have used as amplification target $H$. pylori vacA gene that, besides having no homology to other bacterial species, is present in all $H$. pylori strains. The primers used are well established and their high sensitivity and specificity has been previously demonstrated $[10,11]$. PCR sensitivity was increased by hybridization of amplified products with a specific vacA probe [11].

Considering that PNA-FISH and PCR-DEIA are the most specific and sensitive methods and that all tissue samples analyzed were negative, results obtained by rapid urease test and immunohistochemistry are false positives. Several studies have reported the presence of $H$. pylori in adenoid and/or tonsillar tissues based on the solely use of rapid urease test [6,7]. However, we and others showed that, in cases positive for the rapid urease test, the use of additional detection methods reveals that those are likely falsepositive results $[14,15]$. One very important aspect concerns the specificity of the rapid urease test and of immunohistochemistry. These are related with the probability of the presence in the sample of microorganisms, other than $H$. pylori, that could origin cross reactivity leading to false-positive results. So, although these techniques have a high specificity when used in gastric samples, the specificity may be lower in samples from polymicrobial environments such as the adenotonsillar tissues [14]. The rapid urease test is not in fact a specific test for $H$. pylori, but for ureaseproducing microorganisms. Therefore, the positive results that we have obtained probably reflect the presence in adenotonsillar tissues of other urease-producing bacteria. Likewise, and although immunohistochemistry allows higher reproducibility of $H$. pylori detection in gastric samples when compared with conventional histological techniques [16], in polymicrobial extra gastric samples antibodies can recognize bacterial epitopes other than H. pylori, leading to false-positive results.

The negative results we have obtained by PNA-FISH and PCRDEIA are also in accordance with previously published data using PCR and/or culture [14,15,17-20]. The use of PCR for detection of $H$. pylori in adenotonsillar tissues has sporadically given positive results [21]. However, primer choice needs to be viewed with caution, since certain primer sets used for detection of $H$. pylori produce a very high rate of false-positive results [22].

The main limitation of this study is related with the fact that the gastric infection status of the studied population was only evaluated by IgG serology, which is not specific for active gastric $H$. pylori infection. Therefore, we cannot exclude the possibility that the adenoids and tonsils are infected only in cases of active or recurrent disease. Furthermore, and because $H$. pylori infection is less common in the paediatric population than in adults, the lack of adenotonsillar $H$. pylori infection in children does not exclude this possibility in the adult population.

\section{Conclusion}

The adenotonsillar tissue does not constitute an extra gastric reservoir for $H$. pylori infection, at least a permanent one, in this population of children. Furthermore, techniques currently used for detecting gastric $H$. pylori colonization are not adequate to evaluate infection of the adenotonsillar tissues.

\section{Acknowledgements}

Part of this work was presented at the 22nd Annual Meeting of the European Helicobacter Study Group, Porto, Portugal, September 17-19, 2009. This research was supported by the Portuguese Fundação para a Ciência e a Tecnologia grants SFRH/BD/24579/ 2005 and SFRH/BD/45841/2008. The authors wish to thank Dr. João Anjos, Dr. António Marques, Dr. Mário Carvalho, Dr. Anabela Correia, and the staff of the Serviço de Otorrinolaringologia do Hospital de São Marcos, Braga, for technical assistance and support.

\section{References}

[1] N.F. Azevedo, N. Guimaraes, C. Figueiredo, C.W. Keevil, M.J. Vieira, A new model for the transmission of Helicobacter pylori: role of environmental reservoirs as gene pools to increase strain diversity, Crit. Rev. Microbiol. 33 (2007) 157-169.

[2] N.F. Azevedo, J. Huntington, K.J. Goodman, The epidemiology of Helicobacter pylori and public health implications, Helicobacter 14 (Suppl. 1) (2009) 1-7. 
[3] M. Czesnikiewicz-Guzik, W. Bielanski, T.J. Guzik, B. Loster, S.J. Konturek, Helicobacter pylori in the oral cavity and its implications for gastric infection, periodontal health, immunology and dyspepsia, J. Physiol. Pharmacol. 56 (Suppl. 6) (2005) 77-89.

[4] Y. Liu, H. Yue, A. Li, et al., An epidemiologic study on the correlation between oral Helicobacter pylori and gastric H. pylori, Curr. Microbiol. 58 (2009) 449-453.

[5] B.V. Agirdir, S. Bozova, A.T. Derin, M. Turhan, Chronic otitis media with effusion and Helicobacter pylori, Int. J. Pediatr. Otorhinolaryngol. 70 (2006) 829-834.

[6] B. Khademi, N. Niknejad, B. Gandomi, F. Yeganeh, Comparison of Helicobacter pylori colonization on the tonsillar surface versus tonsillar core tissue as determined by the CLO test, Ear Nose Throat J. 86 (2007) 498-501.

[7] S. Unver, U. Kubilay, O.S. Sezen, T. Coskuner, Investigation of Helicobacter pylori colonization in adenotonsillectomy specimens by means of the CLO test, Laryngoscope 111 (2001) 2183-2186.

[8] N. Guimaraes, N.F. Azevedo, C. Figueiredo, C.W. Keevil, M.J. Vieira, Development and application of a novel peptide nucleic acid probe for the specific detection of Helicobacter pylori in gastric biopsies, J. Clin. Microbiol. 45 (2007) 3089-3094.

[9] L.J. van Doorn, C. Figueiredo, R. Rossau, et al., Typing of Helicobacter pylori vacA gene and detection of cagA gene by PCR and reverse hybridization, J. Clin. Microbiol. 36 (1998) 1271-1276.

[10] L.J. van Doorn, C. Figueiredo, R. Sanna, et al., Expanding allelic diversity of Helicobacter pylori vacA, J. Clin. Microbiol. 36 (1998) 2597-2603.

[11] L.J. van Doorn, Y. Henskens, N. Nouhan, et al., The efficacy of laboratory diagnosis of Helicobacter pylori infections in gastric biopsy specimens is related to bacterial density and vacA, cagA, and iceA genotypes, J. Clin. Microbiol. 38 (2000) 13-17.

[12] M.G. Quina, Helicobacter pylori: the Portuguese scene. Grupo de Estudo Portugues do Helicobacter pylori (GEPHP), Eur. J. Cancer Prev. 3 (Suppl. 2) (1994) 65-67.

[13] M.N. Rodrigues, D.M.M. Queiroz, J.G.B. Filho, L.K. Pontes, R.T. Rodrigues, L.L.B.C. Braga, Prevalence of Helicobacter pylori infection in children from an urban community in north-east Brazil and risk factors for infection, Eur. J. Gastroenterol. Hepatol. 16 (2004) 201-205.

[14] M. Bitar, A. Soweid, R. Mahfouz, G. Zaatari, N. Fuleihan, Is Helicobacter pylori really present in the adenoids of children? Eur. Arch. Otorhinolaryngol. 262 (2005) 987992.

[15] M. Bitar, R. Mahfouz, A. Soweid, et al., Does Helicobacter pylori colonize the nasopharynx of children and contribute to their middle ear disease? Acta Otolaryngol. 126 (2006) 154-159.

[16] L. Marzio, D. Angelucci, L. Grossi, M.G. Diodoro, E. Di Campli, L. Cellini, AntiHelicobacter pylori specific antibody immunohistochemistry improves the diagnostic accuracy of Helicobacter pylori in biopsy specimen from patients treated with triple therapy, Am. J. Gastroenterol. 93 (1998) 223-226.

[17] B. Jelavic, M. Bevanda, M. Ostojic, M. Leventic, M. Vasilj, E. Knezevic, Tonsillar colonization is unlikely to play important role in Helicobacter pylori infection in children, Int. J. Pediatr. Otorhinolaryngol. 71 (2007) 585-590.

[18] G. Di Bonaventura, G. Catamo, M. Neri, G. Neri, R. Piccolomini, Absence of Helicobacter pylori in tonsillar swabs from dyspeptic patients, New Microbiol. 23 (2000) 445-448.

[19] A. Pitkaranta, K.L. Kolho, H. Rautelin, Helicobacter pylori in children who are prone to upper respiratory tract infections, Arch. Otolaryngol. Head Neck Surg. 131 (2005) 256-258.

[20] G. di Bonaventura, M. Neri, G. Neri, G. Catamo, R. Piccolomini, Do tonsils represent an extragastric reservoir for Helicobacter pylori infection, J. Infect. 42 (2001) 221-222.

[21] M.Y. Cirak, A. Ozdek, D. Yilmaz, U. Bayiz, E. Samim, S. Turet, Detection of Helicobacter pylori and its CagA gene in tonsil and adenoid tissues by PCR, Arch. Otolaryngol. Head Neck Surg. 129 (2003) 1225-1229.

[22] M. Sugimoto, J.Y. Wu, S. Abudayyeh, et al., Caution regarding PCR detection of Helicobacter pylori in clinical or environmental samples, J. Clin. Microbiol. 47 (2009) 738-742. 